\title{
Strategi pengembangan kawasan ekowisata dengan menggunakan model Community based ecotourism (CBE) di desa Kuala Terusan Kabupaten Pelalawan
}

\author{
Megawati Hari Dwi Jayanti ${ }^{1}$, Sofyan Husein Siregar ${ }^{2}$, Deni Efizon $^{3}$ \\ ${ }^{1,2}$ Pascasarjana Ilmu Lingkungan Program Pascasarjana Universitas Riau \\ ${ }^{3}$ Fakultas Perikanan dan Ilmu Kelautan
}

\begin{abstract}
Community-based ecotourism is one of the efforts in rural development to improve the local economy. The purpose of this study is to analyze the potential for community-based ecotourism development (CBE) in terms of ecological aspects (flora and fauna characteristics, Carrying capacity and waste management) and socio-economic aspects of culture and local community wisdom and formulate CBE development strategies. The study was conducted in April to July 2019 in the area of natural attractions in the village of Kuala Terusan Pelalawan Regency. The method in this study uses a survey method with a qualitative approach. The results of this study are that the flora found in Kuala Terusan is a type of peat forest and freshwater swamp forest so that there are no special flora that are characteristic of the Kuala Terusan Village area, fauna types in Kuala Terusan are reptile animals, mammals, birds and fish species that exist in the Kampar River. Based on the calculation of physical carrying capacity (Physical Carrying Capacity / PCC) PCC values obtained for swimming / snorkeling activities can accommodate 40 people / day. Activities carried out by Kuala Terusan tourist visitors are accompanied by beach tours and family picnics. The family picnic and beach tourism site has a utilization area of 3,000 m2. Carrying capacity that can accommodate tourists for beach tourism activities is 240 people / day. Facilities still need improvements such as in the processing of waste that has not been going well. $C B E$ development strategies that can be carried out include planning CBE development programs, increasing stakeholder knowledge and awareness, formulating the concept of ecotourism with the government and involving community groups, developing food (local snacks typical of the Kuala Terusan region), improving the economy of local communities, utilizing the important issues of natural forest and the sustainability of nature, utilizing and enforcing existing regulations to support the community-based ecotourism development program at Kuala Terusan Village.
\end{abstract}

Keywords: Ecology; Economy; Socia; Culture; Community Based Ecotourism (CBE)

Salah satu objek wisata di Kabupaten Pelalawan adalah Sungai Kampar yang disebut oleh masyarakat setempat dengan sebutan Pantai Kuala Terusan di Desa Kuala Terusan. Saat ini obyek-obyek wisata di Kabupaten Pelalawan belum banyak dikenal oleh wisatawan baik lokal maupun wisatawan mancanegara. Menurut data jumlah wisata yang berkunjung ke obyek wisata Pantai Kuala Terusan pada tahun 2015 sekitar 1.750 pengunjung, terutama saat liburan hari lebaran dan liburan sekolah (Dinas Kebudayaan, Pariwisata, Pemuda dan Olahraga Kabupaten Pelalawan, 2015). Sedangkan pada hari-hari biasa lokasi wisata Kuala Terusan sepi dari pengunjung bahkan tidak ada pengunjung, karena obyek wisata ini belum menjadi target wisatawan.

Desa Kuala Terusan ditempuh hanya 15 menit dari Kota Pangkalan Kerinci memiliki daya tarik wisata yaitu sungai yang landai berpasir putih yang merupakan pertemuan sungai Kampar Hulu dan Kampar Hilir yang saat ini menjadi tujuan objek wisata bagi pengunjung disebut sebagai Pantai Kuala Terusan (KuTe), selain dari itu adanya keindahan flora dan fauna yang masih asri serta suasana yang jauh dari keramaian menjadikan salah satu pilihan untuk wisata bagi masyarakat setempat, selain dari biaya yang murah serta terjangkau jaraknya dengan Kota Pangkalan Kerinci. Selain menikmati panorama sungai, pejalan bisa juga memancing Ikan Toman dan ikan lainnya yang hidup di danau. Di desa ini juga menyediakan masakan dan ikan olahan ibu-ibu setempat sebagai wisata kuliner bagi pengunjung (Pelalawantourism, 2016).

Desa Kuala Terusan merupakan salah satu desa tertua di Kecamatan Pangkalan Kerinci dan masih memegang adat istiadat yang kuat terlihat pada Bulan Ramadhan Sungai Kuala Terusan menjadi event Mandi Balimau. Pengembangannya belum terealisasi secara optimal dan belum ada realiasasi dari dinas pariwisata setempat, pengelolaan wisata masih dikelola oleh pihak swasta dan masyarakat setempat. Salah satu upaya pengembangan pariwisata di Kuala Terusan tersebut yaitu dengan pengembangan wisata berbasis masyarakat.

Adanya wisata yang belum optimal dan strategi pengembangan ekowisata, dapat meningkatkan ekonomi daerah terutama peningkatan kesejahteraan masyarakat lokal. Hal ini sejalan dengan bagian prinsip ekowisata yaitu dengan meminimalkan dampak kerusakan terhadap lingkungan. Penerapan pariwisata berbasis masyarakat atau community based tourism (CBT) merupakan suatu pendekatan 
pembangunan pariwisata dengan perencanaan yang partisipatif. Definisi CBT adalah model pariwisata yang melibatkan masyarakat lokal dengan memberi kesempatan dalam mengelola dan membangun pariwisata, baik secara langsung maupun tidak langsung yang memiliki keterkaitan dengan industri atau usaha pariwisata, sehingga distribusi keuntungan merata kepada komunitas di pedesaan/ pesisir dan pulau-pulau kecil Putra (2015) dalam Nurdin (2016).

Prinsip obyek wisata yang berbentuk ekowisata ini dikembangkan dengan pariwisata berkelanjutan (sustainable tourism) dengan pemberdayaan masyarakat lokal sehingga masyarakat dapat mengelola aset pariwisata desa, tidak saja sebagai objek tetapi sekaligus menjadi subjek/pelaku, ekowisata bukan menyebabkan perubahan nilai-nilai koservasi, pemberdayaan masyarakat dan ekonomi dapat terwujud dengan sendirinya.

Pengelolaan ekowisata yang berbasis masyarakat dalam pengembangannya memerlukan strategi yang spesifik. Untuk menentukan strategi pengembangan, ekowisata yang berbasis masyarakat meliputi beberapa tahapan yaitu tahapan perencanaan, tahapan pelaksanaan dan tahapan evaluasi (Suansri, 2003 dalam Syafii, 2015). Keberhasilan dan berkembangnya ekowisata haruslah berbasis kepada wisata yang ramah lingkungan dan ekowisata adalah tentang menciptakan dan memuaskan suatu keinginan akan alam, tentang mengeksploitasi potensi wisata untuk konservasi dan pembangunan dan tentang mencengah dampak negatifnya terhadap ekologi, kebudayaan dan keindahan. Sehingga penulis tertarik untuk meneliti tentang "Strategi Pengembangan Kawasan Ekowisata Berdasarkan Model Community Based Ecotourism (CBE) di Desa Kuala Terusan Kabupaten Pelalawan".

\section{METODA PENELITIAN}

Penelitian ini dilaksanakan pada bulan April sampai dengan Juli 2019 di kawasan objek wisata alam Desa Kuala Terusan Kabupaten Pelalawan. Metode penelitian ini adalah metode survei dengan pendekatan kualitatif. Teknik pengumpulan data dilakukan dengan cara observasi, wawancara dan dokumentasi. Analisis data dilakukan dengan SWOT.

\section{HASIL DAN PEMBAHASAN}

\section{Menganalisis Potensi Pengembangan Ekowisata Berbasis Masyarakat (CBE) di Tinjau dari Aspek Ekologi, Aspek Sosial Ekonomi Budaya dan Kearifan Lokal Masyarakat}

\section{Aspek Konservasi}

Flora

Hutan di Desa Kuala Terusan merupakan perpaduan antara hutan rawa gambut dan hutan rawa air tawar yang berada di pinggir sungai. Beberapa flora yang umum ditemukan di hutan Kuala Terusan tersebut dapat dilihat pada tabel 1.

Tabel 1. Jenis Flora di Hutan Kuala Terusan

\begin{tabular}{llll}
\hline No & \multicolumn{1}{c}{ Nama Lokal } & \multicolumn{1}{c}{ Nama Famili } & \multicolumn{1}{c}{ Nama Ilmiah } \\
\hline 1 & Meranti & Dipterocarpaceae & Shorea Uliginosa \\
2 & Pisang-Pisang & Annonaceae & Goniothalamus $S p$ \\
3 & Rengas & Anacardiaceae & Melanorrhoea $S p$ \\
4 & Kelat & Lauraceae & Eugenia $S p$ \\
5 & Medang & Lauraceae & Litsea Angulata \\
6 & Suntai & Sapotaceae & Palaquium Burkii \\
7 & Ramin & Thymelaceae & Ganystylus Bancanus \\
8 & Resak & Dipterocarpaceae & Vatica Sp \\
9 & Mahang & Euphorbiaceae & Macaranga Triloba \\
10 & Cempedak Hutan & Channidae & Channa Micropeltes \\
11 & Akasia & Mimosaceae & Acacia Mangium \\
12 & Rambutan Hutan & Sapindaceae & Nephelium Mutabile \\
\hline
\end{tabular}

\section{Fauna}

Sumber: Data BPTSTH 2015

Fauna yang ditemukan di Desa Kuala Terusan terdiri dari hewan mamalia, hewan jenis reptil, hewan jenis burung serta ikan yang terdapat pada Daerah Aliran Sungai Kampar yaitu:

a. Hewan Mamalia

Hewan mamalia di Desa Kuala Terusan tidak banyak jenisnya karena sudah jarang dijumpai lagi keberadaannya untuk mamalia hutan seperti didaerah lainnya. Jenis hewan yang masih sering dijumpai 
adalah monyet ekor panjang apabila saat musim buah tiba. Jenis hewan mamalia yang ada di Kuala Terusan pada tabel 2 .

Tabel 2. Jenis Hewan Mamalia di Hutan Kuala Terusan

\begin{tabular}{clll}
\hline No & \multicolumn{1}{c}{ Nama Lokal } & \multicolumn{1}{c}{ Nama Famili } & \multicolumn{1}{c}{ Nama Ilmiah } \\
\hline 1 & Monyet Ekor Panjang & Cercopithecidae & Macaca Fascicularis \\
2 & Beruk & Cercophitecidae & Macaca Nemestrina \\
3 & Siamang & Hylobatidae & Hylobates Syndactylus \\
4 & Tupai & Tupaidae & Ncalisciurus Notalus \\
5 & Bajing & Sciuridae & Petaurus Sp \\
6 & Kalong & Pteropodidae & Pteropus Edulis \\
7 & Kelelawar & Pteropodidae & Cynopterus Sp \\
8 & Babi Hutan & Suidae & Sus Scrofa \\
\hline Sumber: Data BPTSTH 2015 & &
\end{tabular}

b. Hewan Reptil

Jenis reptil yang masih sering di jumpai oleh masyarakat maupun pengunjung di Desa Kuala Terusan adalah hewan biawak dan kadal. Hewan tersebut menyusuri sungai untuk mencari ikan. Jenis hewan reptil di kawasan hutan Kuala Terusan disajikan pada tabel 3.

Tabel 3. Jenis Hewan Reptil di Hutan Kuala Terusan

\begin{tabular}{clll}
\hline No & \multicolumn{1}{c}{ Nama Lokal } & \multicolumn{1}{c}{ Nama Famili } & \multicolumn{1}{c}{ Nama Ilmiah } \\
\hline 1 & Biawak & Varanidae & Varanus Salvator \\
2 & Kadal & Lacertidae & Mabouya Sp \\
3 & Ular Sawah & Boidae & Phyton $S p$ \\
4 & Ular Kobra & Eladae & Naja Sp \\
5 & Ular Kadut & Viperidae & Acrohordus $S p$ \\
6 & Ular Tiung & Viperidae & Trimeresurus $S p$ \\
7 & Kura-Kura & Geoemydidae & Cuora Amboinensis \\
\hline Sumber: Data BPTSTH 2015 & &
\end{tabular}

c. Jenis Burung

Jenis burung di hutan Kuala Terusan memiliki banyak jenis dibanding dengan jenis hewan mamalia dan reptile. Bahkan burung-burung tersebut masih sering beterbangan di kawasan wisata Kuala Terusan. Burung yang masih sering dijumpai yaitu burung bangau dan burung belibis sebagai hewan pemakan ikanikan kecil. Sedangkan untuk burung Enggang sudah jarang di temukan. Jenis burung di kawasan hutan Kuala Terusan disajikan pada tabel 4.

Tabel 4. Jenis Burung di Hutan Kuala Terusan

\begin{tabular}{llll}
\hline No & \multicolumn{1}{c}{ Nama Lokal } & \multicolumn{1}{c}{ Nama Famili } & \multicolumn{1}{c}{ Nama Ilmiah } \\
\hline 1 & Ruak-Ruak & Ciconiidae & Pseudibis Gigantean \\
2 & Bangau Putih & Ardeidae & Egretta Ibis Intermedia \\
3 & Burung Undan & Ciconidae & Ciconia Episcopus \\
4 & Belibis & Anatidae & Dendrocygna Javanica \\
5 & Raja Udang Biru & Alcedinidae & Halcyon Cyanoventris \\
6 & Raja Udang Besar & Alcedinidae & Pelargopsis Capensis \\
7 & Enggang Beguk & Bucerotidae & Aceros Undulatus \\
8 & Enggang Ekor Hitam & Bucerotidae & Annorhinus Galeritus \\
9 & Jalak & Sturnidae & Leucopsar Rothschildi \\
10 & Elang & Accipitridae & Henicopernislongicauda \\
11 & Perenjak & Turdidae & Prinia Familiaris Olivacea \\
12 & Bubut Merah & Duculidae & Collocalia Esculenta \\
13 & Pelatuk Merah Kuning & Picidae & Centropus Sisnensis \\
14 & Sri Gunting & Dicruridae & Chrysocoleptes Sp \\
15 & Gagak & Corvidae & Corvus Corone \\
16 & Ayam Hutan & Phasianidae & Gallus Gallus \\
17 & Balam & Columbidae & Streptopelia Chinensis \\
18 & Punai & Columbidae & Treron Curvirostra \\
19 & Pipit & Ploceidae & Lonchura Leucogastroides \\
20 & Burung Gereja & Ploceidae & Passer Montanus \\
\hline Sumber: Data BPTSTH 2015 & &
\end{tabular}




\section{ZONA}

Jurnal Lingkungan

Volume 4, No 2, Oktober 2019, p. 58-70

ISSN : 2502-6496 (Print)

http://zona.pelantarpress.co.id

d. Jenis Ikan

Jenis-jenis ikan yang ada di sungai Kuala Terusan bergantung pada musim ikan tersebut bertelur atau menetas. Ikan-ikan tersebut masih sering didapat oleh para pengunjung pemancing, sehingga kawasan/sungai tersebut masih dikunjungi oleh pemancing baik dari lokal maupun dari luar wilayah Kabupaten Pelalawan. Para pengunjung pemancing datang saat air jernih dan kondisi air baik. Jenis ikan di Kuala Terusan dapat dilihat pada tabel 5.

Tabel 5. Jenis Ikan di Sungai Kuala Terusan

\begin{tabular}{llll}
\hline No & \multicolumn{1}{c}{ Nama Lokal } & \multicolumn{1}{c}{ Nama Famili } & \multicolumn{1}{c}{ Nama Ilmiah } \\
\hline 1 & Tapah & Siluridae & Walliago Sp \\
2 & Baung & Bragiidae & Macrones Sp \\
3 & Gabus & Channidae & Ophiocephalus Striatus \\
4 & Sepat Mutiara & Belontiidae & Trichogaster Leeri \\
5 & Tempalo & Belontiidae & Betta Sp \\
6 & Pantau, Pepuyu & Cyprinidae & Rasbora Trilineata \\
7 & Betok & Anabantidae & Anabas Testudineus \\
8 & Sepat Siam & Belontidae & Trichagaster Pectoralis \\
9 & Bujuk & Channidae & Channa Lusius \\
10 & Toman & Channidae & Chnna Micropeltes \\
11 & Selais & Siluridae & Cryptopterus Sp \\
12 & Belida & Notopteridae & Nothopterus Sp \\
13 & Tuakang & Helostomatidae & Helostoma Temminckii \\
14 & Udang Galah & Palaemonidae & Macrobrachium Rosenbergii \\
15 & Patin & Pangasidae & Pangasius Nasutus \\
16 & Juaro & Pangasidae & Pangasius Polyuranodos \\
17 & Betutu & Eleotridae & Oxyeleotris Marmorata \\
18 & Tilan/Ikan Sili & Mastacembelidae & Mastacembelus Argus \\
19 & Pari Air Tawar & Dasyatidae & - \\
20 & Jalai/Kerandang/Serandang & Channidea & Channa Striata \\
21 & Gurame & Osphronemidae & - \\
22 & Sebarau/Hampala & Cyprinidae & Hampala Macrolepidota \\
\hline
\end{tabular}

Sumber: Data BPTSTH 2015

\section{Daya Dukung Lingkungan}

Fisik

Daya dukung kawasan wisata merupakan batasan suatu kawasan yang mampu menampung jumlah wisatawan dengan kegiatan wisatanya. Daya dukung merupakan cara menerapkan konsep dimana ada pembatasan dalam pemanfaatan sumberdaya. Kegiatan wisatawan tidak terlepas dari pemanfaatan sumberdaya, sehingga diperlukan perhitungan dan analisis yang dapat mengakomodasi tingkat kepuasan wisatawan yang tertinggi dan berdampak minimal terhadap sumberdaya.

Daya dukung kawasan disesuaikan dengan karakteristik sumberdaya dan peruntukannya. Untuk kegiatan wisata seperti snorkeling/berenang, kebutuhan manusia akan ruang horizontal untuk dapat bergerak bebas dan tidak merasa terganggu oleh keberadaan manusia (wisatawan) lainnya. Sementara untuk aktivitas wisata pantai, disetiap orang membutuhkan ruang gerak untuk berjemur, menikmati pemandangan, berjalan-jalan dan lain-lain (Yulianda et al 2010).

Potensi ekologis wisatawan adalah kemampuan alam untuk menampung wisatawan Potensi ekologis dan luas unit area untuk setiap jenis kegiatan wisata bahari ditunjukkan pada Tabel 6 (Yulianda 2007).

Tabel 6. Potensi Ekologis Wisatawan Per Satuan Unit Area (K) Dan Luas Unit Area (Lt)

\begin{tabular}{|c|c|c|c|}
\hline Jenis Kegiatan & $\begin{array}{c}\sum \text { Pengunjung } \\
(\mathrm{K})\end{array}$ & $\begin{array}{l}\text { Unit Area } \\
\text { (Lt) }\end{array}$ & Keterangan \\
\hline Snorkeling & 1 & $500 \mathrm{~m}^{2}$ & Setiap 1 orang dalam $100 \mathrm{~m} \times 5 \mathrm{~m}$ \\
\hline Rekreasi pantai & 1 & $50 \mathrm{~m}$ & 1 orang setiap $50 \mathrm{~m}$ panjang pantai \\
\hline
\end{tabular}

Kegiatan pengunjung (Wp) dihitung berdasarkan lamanya waktu yang dihabiskan pengunjung untuk melakukan kegiatan wisata, yaitu 2 jam untuk aktivitas snorkeling/berenang dan 3 jam untuk aktivitas wisata pantai. Waktu kawasan (Wt) adalah lama waktu areal yang dibuka dalam satu hari di kawasan wisata Kuala Terusan, yaitu 8 jam untuk aktivitas snorkeling/Berenang dan 12 jam untuk aktivitas wisata pantai. Data dapat dilihat pada tabel 7. 


\section{ZONA}

Jurnal Lingkungan

Volume 4, No 2, Oktober 2019, p. 58-70

ISSN : 2502-6496 (Print) http://zona.pelantarpress.co.id

Tabel 7. Potensi Ekologis Wisatawan di Kuala Terusan

\begin{tabular}{|c|c|c|c|c|c|c|c|}
\hline No & Aktivitas & $\begin{array}{l}\mathrm{K}^{*} \\
\text { (a) }\end{array}$ & $\begin{array}{l}\mathrm{Lp} \\
\text { (b) }\end{array}$ & $\begin{array}{l}\mathrm{Lt}^{*} \\
\text { (c) }\end{array}$ & $\begin{array}{l}\text { Wp } \\
\text { (d) }\end{array}$ & $\begin{array}{l}\text { Wt } \\
\text { (e) }\end{array}$ & $\begin{array}{c}\text { DDK } \\
\mathrm{a} \times(\mathrm{b} / \mathrm{c}) \times(\mathrm{e} / \mathrm{d})\end{array}$ \\
\hline 1 & Berenang & 1 & $5000 \mathrm{~m}^{2}$ & $500 \mathrm{~m}^{2}$ & $2 /$ jam & $8 / \mathrm{jam}$ & 40 orang/jam \\
\hline 2 & Pantai & 1 & $3000 \mathrm{~m}^{2}$ & $50 \mathrm{~m}^{2}$ & $2 / \mathrm{jam}$ & $8 /$ jam & 240 orang/jam \\
\hline 3 & Piknik & 1 & $3000 \mathrm{~m}^{2}$ & $50 \mathrm{~m}^{2}$ & $2 / \mathrm{jam}$ & $8 /$ jam & 240 orang/jam \\
\hline
\end{tabular}

Sumber : Yulianda, 2007

Potensi ekologis wisatawan untuk aktivitas berenang adalah satu orang dengan unit area $500 \mathrm{~m}^{2}$. Artinya, dalam luasan $500 \mathrm{~m}^{2}$ dapat menampung aktivitas berenang untuk satu orang. Rata-rata waktu yang dibutuhkan wisatawan untuk kegiatan snorkeling adalah 2 jam dengan total waktu yang disediakan dalam sehari adalah 8 jam per hari.

Sungai Kuala Terusan yang digunakan untuk area pemanfaatan berenang seluas $5.000 \mathrm{~m}^{2}$. Luas area pemanfaatan sebesar ini dapat menampung 40 orang/hari. Artinya, dengan total waktu 8 jam yang disediakan kawasan selama satu hari, dan waktu yang digunakan wisatawan untuk berenang selama 2 jam, maka jumlah wisatawan yang dapat ditampung untuk aktivitas berenang pada lokasi tersebut adalah 40 orang dalam satu hari. aktivitas berenang di Kuala Terusan ini dapat dikategorikan over carrying capacity karena jumlah wisatawan yang melakukan aktivitas wisata melebihi daya tampung yang tersedia.

Jumlah rata-rata kunjungan wisatawan yang mengunjungi Wisata Kuala Terusan per hari adalah 1.000-2.000 orang pada saat hari libur dan kunjungan wisatawan melakukan aktifitas memancing, wisata sampan hias dan kunjungan ke Desa Kuala Terusan, angka ini diperoleh dari wawancara pemilik Wisata Kuala Terusan dan pada saat hari biasa kunjungan wisatawan kurang dari 200 orang (Sumber; Aspan Dendi Pengelola Wisata Kuala Terusan; 2019).

Jumlah wisatawan yang melakukan aktivitas berenang adalah 146 orang, angka ini diperoleh dari pendekatan jumlah responden wisatawan yang melakukan aktivitas berenang di Pantai Kuala Terusan. Kondisi over carrying capacity di kawasan wisata Kuala Terusan terjadi pada akhir pekan atau hari libur (peak season). Jumlah kunjungan lebih banyak di hari libur dari pada hari kerja, karena umumnya wisatawan yang berkunjung adalah pegawai swasta keluarga, dan pelajar yang memiliki waktu luang hanya akhir pekan dan hari libur. Sementara itu, diluar peak season aktivitas wisata di Kuala Terusan tidak terlalu ramai dan masih dapat menampung aktivitas wisata berenang.

Aktivitas wisata pantai adalah aktivitas yang juga banyak diminati oleh wisatawan selain wisata berenang. Potensi ekologis wisatawan untuk wisata pantai adalah satu orang dengan unit area $50 \mathrm{~m}$, atau dengan kata lain satu orang dapat melakukan aktivitas wisata pantai setiap $50 \mathrm{~m}$ panjang pantai. Rata-rata waktu yang dibutuhkan wisatawan untuk kegiatan wisata pantai adalah 3 jam dengan total waktu yang disediakan dalam sehari adalah 12 jam per hari.

Aktifitas yang dilakukan oleh para pengunjung wisata Kuala Terusan diantaranta wisata pantai dan piknik keluarga. Lokasi piknik keluarga dan wisata pantai memiliki area pemanfaatan seluas $3.000 \mathrm{~m}^{2}$. Daya dukung yang dapat menampung wisatawan untuk aktivitas wisata pantai adalah sebanyak 240 orang/ hari. Artinya dalam waktu yang bersamaan, dengan total waktu 12 jam yang disediakan kawasan selama satu hari, dan waktu yang digunakan wisatawan untuk kegiatan wisata pantai selama 3 jam, maka jumlah yang dapat ditampung pada lokasi tersebut adalah 240 orang dalam satu hari.

Namun apabila wisatawan hanya menggunakan waktu untuk wisata pantai dan piknik keluarga kurang dari 3 jam, maka daya dukung dapat menampung lebih dari 240 orang dalam sehari. Apabila diasumsikan seluruh wisatawan melakukan aktivitas wisata Kuala Terusan, maka jumlah kunjungan wisatawan ke Pantai Kuala Terusan melebihi daya dukung yang tersedia. Sama hal nya dengan aktivitas berenang, kondisi di lokasi menunjukkan kepadatan terjadi hanya pada saat peak season. Pada saat hari kerja, kunjungan wisata cukup normal.

\section{Sosial Psikologi Pengunjung}

Sosial psikologi pengunjung dilakukan untuk mengetahui tingkat kenyamanan dan kepuasan pengunjung. Sosial psikologi pengunjung diketahui dengan pemberian kuesioner kepada pengunjung. 


\section{ZONA}

Jurnal Lingkungan

Volume 4, No 2, Oktober 2019, p. 58-70

ISSN : 2502-6496 (Print)

http://zona.pelantarpress.co.id

\section{Kenyamanan Pengunjung}

Berdasarkan hasil kuesioner yang telah dibagikan, diketahui bahwa sebagian besar pengunjung berkunjung dengan keluarga, namun hanya sebagian kecil pengunjung yang mendatangi taman wisata ini lebih dari dua kali. Sebagian besar pengunjung.

\section{Kepuasan Pengunjung}

Kepuasan pengunjung merupakan salah satu indikator pariwisata berkelanjutan (Santoso, 2014). Berdasarkan hasil kuesioner yang telah dibagikan, diketahui bahwa sebagian besar pengunjung menikmati objek wisata 2-4 jam, sebagian besar pengunjung juga merasa jarak/luasan 4-6 meter dibutuhkan untuk wisatawan agar merasa nyaman serta sebagian besar pengunjung merasa puas. Namun hanya sebagian kecil pengunjung yang ingin mengulangi kunjungan di lain waktu, serta sebagian besar pengunjung merasa pelayanan petugas atau pengelola belum baik. Sebagian besar pengunjung merasa kondisi fasilitas sarana dan prasarana tidak dalam keadaan baik.

Kepuasan pengunjung berkaitan dengan fasilitas serta pelayanan yang diberikan. Sebagian besar pengunjung masih merasa pelayanan petugas atau pengelola belum baik. Pengembangan kawasan ekowisata daerah ini harus berbasis masyarakat. Selain itu juga perlu dilakukan perbaikan sarana dan prasarana di kawasan ekowisata, upaya konservasi/reboisasi dalam upaya perbaikan kondisi lingkungan juga dianggap perlu.

Fasilitas pendukung yang harus disediakan agar para pengunjung dapat memperoleh kepuasan dan kenyamanan dalam berwisata diantaranya tong sampah, mushalla, toilet, tempat istirahat, kios kuliner dan cenderamata serta tempat parkir. Area yang digunakan pada lahan 1 ha di wisata Kuala Terusan yang dipergunakan sebagai fasilitas sarana prasarana dapat dilihat pada tabel 8 .

Tabel 8. Luasan Area wisata Kuala Terusan yang dimanfaatkan

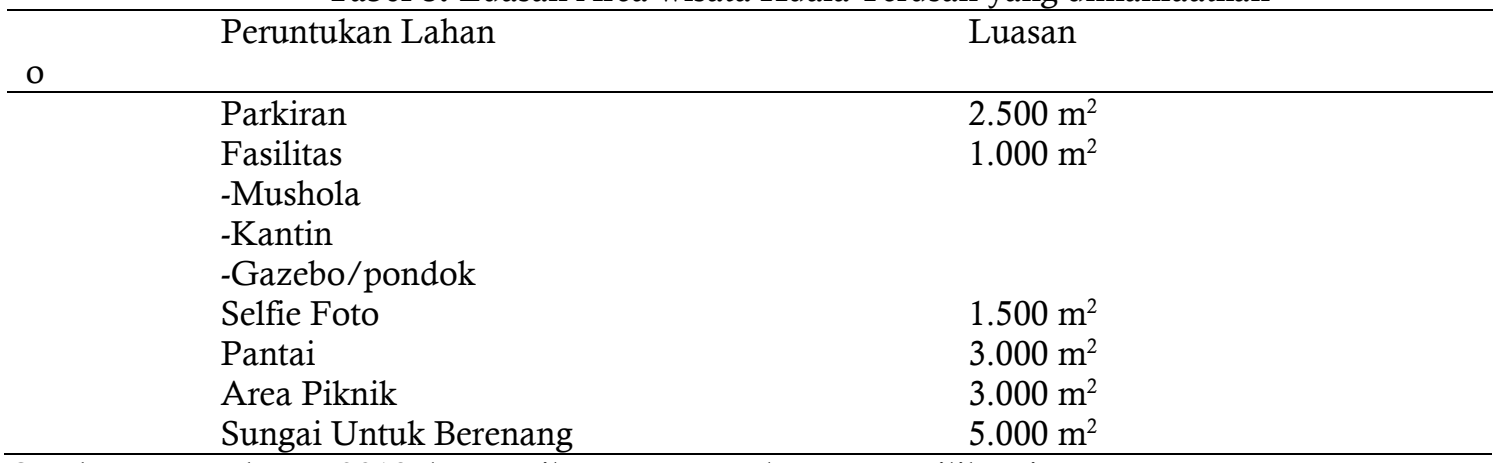

Sumber : Pengukuran 2019 dan Hasil Wawancara dengan Pemilik Wisata

1) Tong Sampah

Tong sampah tersedia di setiap sudut wisata dan setiap pondok terdapat tong sampah. Kebersihan sangat diperhatikan oleh pemilik wisata yang memperkerjakan masyarakat setempat. Namun tidak terdapat pemilahan sampah pada tong sampah yang disediakan. Sampah-sampah yang dikumpulkan petugas kebanyakan dikumpulkan pada satu tempat sampah yang terbuat dari semen yang digunakan untuk membakar sampah.

2) Mushalla

Keberadaan mushalla pada kawasan objek wisata tentu sangat penting peranannya. Pembangunan mushalla sudah dilakukan sebanyak satu unit dan bersebelahan dengan toilet. Namun keberadaan mushalla ini kurang terawat dengan baik yang dapat dilihat dari kurangnya kebersihan mushalla. Mushalla ini jarang digunakan pengunjung karena kebersihan air yang tidak ada sama sekali di tempat pengambilan wudhu maupun toilet. Hal ini tentu saja mengganggu kenyamanan dan menjadi keluhan serius dari para pengunjung.

3) Toilet

Toilet pada kawasan objek wisata sangat penting peranannya. Toilet yang disediakan berada dekat dengan pintu masuk dengan jumlah yang tidak memadai yaitu hanya satu unit. Toilet ini juga sangat tidak terawat dengan baik. Selain itu pintu toilet ini juga sudah rusak dan tidak bisa ditutup dari dalam. Hal ini juga dikeluhkan pengunjung sehingga mengganggu kenyamanan para pengunjung.

4) Tempat istirahat

Tempat istirahat terletak di kawasan ekowisata dan biasanya digunakan para pengunjung setelah berkeliling taman ekowisata. Tempat beristirahat ini terdiri berupa pondok-pondok di pinggir sungai atau pantai yang disewakan oleh pemilik wisata. Selain itu, tempat istirahat juga berupa tikar yang dibawa oleh para wisatawan dan digelar di bawah pohon-pohon sawit. Pengunjung juga dapat 


\section{ZONA}

Jurnal Lingkungan

Volume 4, No 2, Oktober 2019, p. 58-70

ISSN : 2502-6496 (Print)

http://zona.pelantarpress.co.id

menikmati makanan dan minuman dari para pedagang yang berjualan disekitarnya. Kuliner dilakukan dengan memesan terlebih dahulu masakan khas tempatan seperti gulai, asam pedas dan ikan sungai. Selain itu, tempat beristirahat lainnya disediakan tidak jauh dari area mushalla dan toilet. Pondok istirahat ini sampai sekarang masih dapat digunakan sebagaimana mestinya. Namun jumlahnya terbatas sehingga tidak dapat menampung terlalu banyak para pengunjung yang ingin beristirahat di tempat ini. Masyarakat perlu menambah pondok istirahat ini agar dapat mencukupi jumlahnya sehingga pengunjung lainnya juga mendapatkan tempat yang layak untuk beristirahat.

5) Kios kuliner dan cenderamata

Kios kuliner dan cenderamata telah disediakan oleh masyarakat dimana keberadaanya terletak 2 buah didalam tempat wisata dan di pintu masuk taman ekowisata. Kios-kios ini hanya terbuat dari terpal dengan kursi-kursi yang telah disediakan untuk pengunjung. Namun fasilitas kios kuliner dan cenderamata ini belum dimanfaatkan dengan baik oleh para pedagang. Untuk fasilitas kios kuliner atau makanan dan minuman jumlahnya sangat terbatas. Hanya ada satu dua orang pedagang saja yang menjual makanan dan minuman setiap harinya. Jumlahnya sangat terbatas dengan menu kuliner yang sangat terbatas.

Pada hari-hari besar atau hari tertentu jumlah pedagang musiman meningkat. Penataan pedagang dan pertokoan di sepanjang jalan setapak kurang teratur karena berjualan dengan mendirikan tenda disekitar jalan setapak. Sementara untuk kios cenderamata belum ada sama sekali disediakan. Menu kuliner dapat dipesan oleh wisatawan seperti makanan khas daerah setempat yang dimasak oleh warga PKK Desa Kuala Terusan.

6) Tempat parkir

Tempat parkir yang tersedia berupa halaman dan lapangan yang beralaskan rumput-rumput yang setiap harinya dipangkas dan dikelilingi oleh pohon sawit. Tempat parkir yang tersedia hanya di halaman atau lapangan yang telah disediakan dengan luas yang mencukupi pada hari-hari biasa. Tempat parkiri ini masih dapat digunakan dengan baik oleh para pengunjung dan terawat dengan baik karena setiap sore dibersihkan oleh para pekerja.

7) Arena wisata

Arena wisata yang disajikan di Desa Kuala Terusan yaitu spot selfie, pemandangan sungai, mandi dan berenang di sungai, memancing, penyewaan perahu hias untuk berwisata mengitari sungai.

\section{Kebersihan/Persampahan}

Kebersihan di wilayah ekowisata Desa Kuala Terusan kurang terjaga. Pekerja kebersihan hanya menyapu dan mengumpulkan sampah-sampah setiap sore hari. Selama itu, ketika pengunjung berada di kawasan ekowisata, banyak sampah yang bertebaran karena tempat sampah yang tersedia juga kurang. Setiap tiga hari sekali, rumput dipotong. Tong sampah juga telah disediakan di setiap tempat sudut wisata terutama di dekat kios kuliner atau kedai dan pondok.

Namun tong sampah yang tersedia tidak terdapat pemilahan sampah seperti pemilahan sampah organik dan anorganik. Sampah-sampah yang dikumpulkan petugas kebanyakan dikumpulkan pada satu tempat sampah yang terbuat dari semen yang digunakan untuk membakar sampah.

\section{Sosial Budaya dan Sosial Ekonomi Masyarakat Sosial Budaya Kearifan Lokal}

Masyarakat di sekitar objek wisata berperan penting tidak hanya dalam proses pelaksanaan wisata secara langsung tetapi juga dalam pengelolaan kawasan wisata tersebut nantinya. Peran masyarakat dibutuhkan dalam masyarakat sadar wisata.

Wisata di Desa Kuala Terusan sebagian besar diisi oleh masyarakat. Mulai dari para pedagang, petugas kebersihan hingga tukang parkir telah diisi oleh masyarakat. Selain itu masyarakat juga turut meramaikan jika ada acara-acara besar di wilayah tersebut.

Bentuk-bentuk kearifan lokal yang ada di masyarakat Desa Kuala Terusan berupa nilai, norma, kepercayaan, dan aturan-aturan khusus. Bentuk yang bermacam-macam ini mengakibatkan fungsi kearifan lokal menjadi bermacam-macam pula. Fungsi kearifan lokal tersebut antara lain untuk: (1) konservasi dan pelestarian sumber daya alam; (2) mengembangkan sumberdaya manusia; (3) pengembangan kebudayaan dan ilmu pengetahuan; serta (4) petunjuk tentang petuah, kepercayaan, sastra, dan pantangan.

Kehidupan sosial yang diterapkan di masyarakat Desa Kuala Terusan dapat dilihat dari kehidupan sehari-harinya. Masyarakat Desa Kuala Terusan saling tolong menolong serta bergotong royong jika ada yang memerlukan bantuan, biasanya terjadi jika masyarakat setempat akan mengadakan acara syukuran, pernikahan, maupun kemalangan yang terjadi pada salah satu keluarga. 


\section{ZONA}

Jurnal Lingkungan

ISSN : 2502-6496 (Print)

Selain itu masyarakat Desa Kuala Terusan juga berpegang tegus pada adat istiadat ini terbukti dari masih adanya adat istiadat yang masih dilestarikan hingga saat sekarang ini. Termasuk objek wisata budaya diantaranya adalah pola kehidupan masyarakat di Desa Kuala Terusan seperti tradisi, adat istiadat pakaian, upacara dan kebiasaan masyarakatnya. Adat istiadat yang dilakukan oleh masyarakat Desa Kuala Terusan sampai saat ini adalah perahu beganduang, manjompuik limau, tradisi turun mandi, adat perkawinan, acara bulian dan tolak bala atau meminta hujan.

\section{Aspek Ekonomi Masyarakat}

Adanya kegiatan wisata di suatu lokasi akan berdampak luas ke wilayah disekitarnya. Ekowisata pada suatu daerah dapat menjadi sumber pendapatan yang memberikan manfaat bagi publik. Namun kontribusi ekowisata terhadap perekonomian wilayah tidak hanya pada seberapa banyak uang yang mengalir ke wilayah tersebut, tetapi juga seberapa banyak orang yang datang dan tinggal di wilayah tersebut dan menghasilkan dampak yang luas (multiple effects).

Selain sebagai wabah edukasi lingkungan dalam hal meningkatkan pemahaman seluruh pihak terkait pentingnya pemanfaatan lingkungan secara berkelanjugan, penerapan strategi pengelolaan ekowisata juga akan berdampak langsung ekonomi masyarakat setempat. Pembangunan masyarakat setempat ini bermakna sebagai upaya memperkuat kelompok-kelompok masyarakat setempat untuk mengontrol dan mengelola sumber daya yang sangat bernilai dengan cara-cara yang tidak hanya dapat melestarikan sumber daya akan tetapi juga mampu memenuhi kebutuhan kelompok tersebut secara ekonomi.

Dampak pengembangan ekowisata Desa Kuala Terusan bagi ekonomi masyarakat dapat meningkatkan taraf hidup masyarakat sebab ekowisata akan melibatkan masyarakat di dalam kegiatannya selain itu, kehadiran wisatawan juga akan menjadi konsumen baru bagi para pedagang dan penjual jasa. Hal ini akan berdampak pada taraf hidup masyarakat setempat.

Berdasarkan beberapa pemahaman tersebut, maka dapat disimpulkan bahwa ekowisata Desa Kuala Terusan sebagai salah satu objek wisata alam di Kabupaten Pelalawan kondisinya saat ini kurang terawat dan kurang pengelolaannya terhadap fasilitas objek wisata tersebut. Sehingga banyak pengunjung yang datang ke objek wisata tersebut tidak dapat menikmati fasilitas yang disediakan oleh pengelola. Karena terlihat di objek wisata tersebut fasilitas-fasilitas yang disediakan oleh pengelola kondisinya sudah rusak dan tidak bisa digunakan lagi.

Sesuai dengan pendapat salah satu masyarakat yang menyatakan bahwa fasilitas publik objek wisata kurang baik. Perlu adanya campur tangan pemerintah. Selama ini belum ada regulasi yang jelas dari pemerintah. Pengelola perlu bekerja sama dengan pemerintah untuk mencapai ekowisata berbasis masyarakat, serta terus meningkatkan pelayanan publik di daerah wisata seperti kebersihan, kenyamanan dan pelayanan sehingga dapat meningkatkan jumlah wisatawan.

Berdasarkan hasil wawancara dengan pengelola, jumlah wisatawan yang ada pada hari biasa kurang dari 200 pengunjung per hari. Hari sabtu minggu umumnya 1.000-2.000 per hari, jumlah wisatawan pada bulan Ramadhan atau hari-hari besar mencapai 3.000-4.000 pengunjung per hari. Jika kenyamanan dan pelayanan ditingkatkan, diharapkan jumlah wisatawan akan semakin meningkat sehingga diharapkan pendapatan pariwisata serta sosial ekonomi masyarakat dapat meningkat juga.

Fasilitas yang disediakan oleh pihak pengelola dapat dikatakan masih belum mencukupi untuk memenuhi kebutuhan pengunjung. Apabila dibandingkan dengan fasilitas yang ada, seharusnya fasilitas yang disediakan oleh pengelola disesuaikan dengan jumlah pengunjung yang datang ke ekowisata Desa Kuala Terusan dan fasilitas yang ada harus dirawat karena fasilitas yang ada kondisinya sangat buruk dan banyak yang sudah rusak. Pemerintah Kabupaten perlu terus meningkatkan pelayanan publik di daerah wisata seperti kebersihan, kenyamanan, keamanan dan pelayanan sehingga dapat meningkatkan jumlah wisatawan.

Spillane (2010) mengatakan bahwa salah satu hal penting untuk pengembangan pariwisata adalah kemudahan berupa fasilitas. Tidak jarang wisatawan berkunjung ke suatu tempat karena merasa mendapat suatu kemudahan seperti mendapatkan informasi, mengurus dokumen perjalanan, membawa barang atau uang dan sebagainya. Fasilitas merupakan sarana prasarana yang mendukung operasional objek wisata untuk mengakomodasikan segala kebutuhan wisatawan, tidak secara langsung mendorong pertumbuhan tetapi berkembang pada saat yang sama atau sesudah atraksi berkembang. Pemerintah Kabupaten Pelalawan perlu terus meningkatkan pelayanan publik di daerah wisata seperti kebersihan, kenyamanan dan pelayanan sehingga dapat meningkatkan jumlah wisatawan. 
Tidak dapat dipungkiri bahwa aktifitas pembangunan fasilitas di kawasan pariwisata dapat menimbulkan dampak terhadap alam dan lingkungan. Hal ini harus menjadi perhatian besar agar pembangunan tidak berdampak negatif bagi lingkungan. Menurut Richardson dan Fluker (dalam Purba, 2002), pariwisata dapat berdampak terhadap lingkungan karena penggunaan alat transportasi yang menjadi sumber utama polusi udara, polusi suara dan pemanasan global, dampak akibat pembangunan fasilitas pariwisata berupa sedimentasi dan emisi gas buang dimana pembangunan di daerah perbukitan dapat mengakibatkan perusakan hutan, erosi dan longsor serta habitat binatang liar yang terganggu selama pembangunan fasilitas.

Akibat dampak dari pengoperasian industri pariwisata berupa tekanan terhadap Sumber Daya Alam karena merusak dan menghancurkan vegetasi tumbuhan yang ada di lokasi perjalanan, perusakan habitat kehidupan liar seperti hilangnya habitat untuk pembangunan pariwisata, penyediaan tempat camping serta polusi dan pencemaran limbah lainnya seperti limbah sampah yang dibuang sembarangan. Oleh sebab itu, di satu sisi perlu penambahan fasilitas seperti tong sampah dan penyediaan air bersih namun disisi lain harus diperhatikan dengan sebaik-baiknya dampak pembangunan tersebut terhadap lingkungan.

\section{Merumuskan Strategi Pengembangan Ekowisata Berbasis Masyarakat (CBE) di Desa Kuala Terusan Kabupaten Pelalawan}

Berkaitan dengan strategi pengembangan ekowisata berbasis masyarakat di Desa Kuala Terusan Kabupaten Pelalawan, maka harus dihadapkan pada seperangkat kekuatan, kelemahan, peluang dan ancaman yang perlu diidentifikasi, dipahami dan dianalisis agar dapat dimanfaatkan untuk mendukung pencapaian tujuan.

Tabel 9.Formulasi Matriks SWOT dalam Menentukan Strategi Pengembangan Ekowisata Berbasis Masyarakat di Desa Kualu Terusan

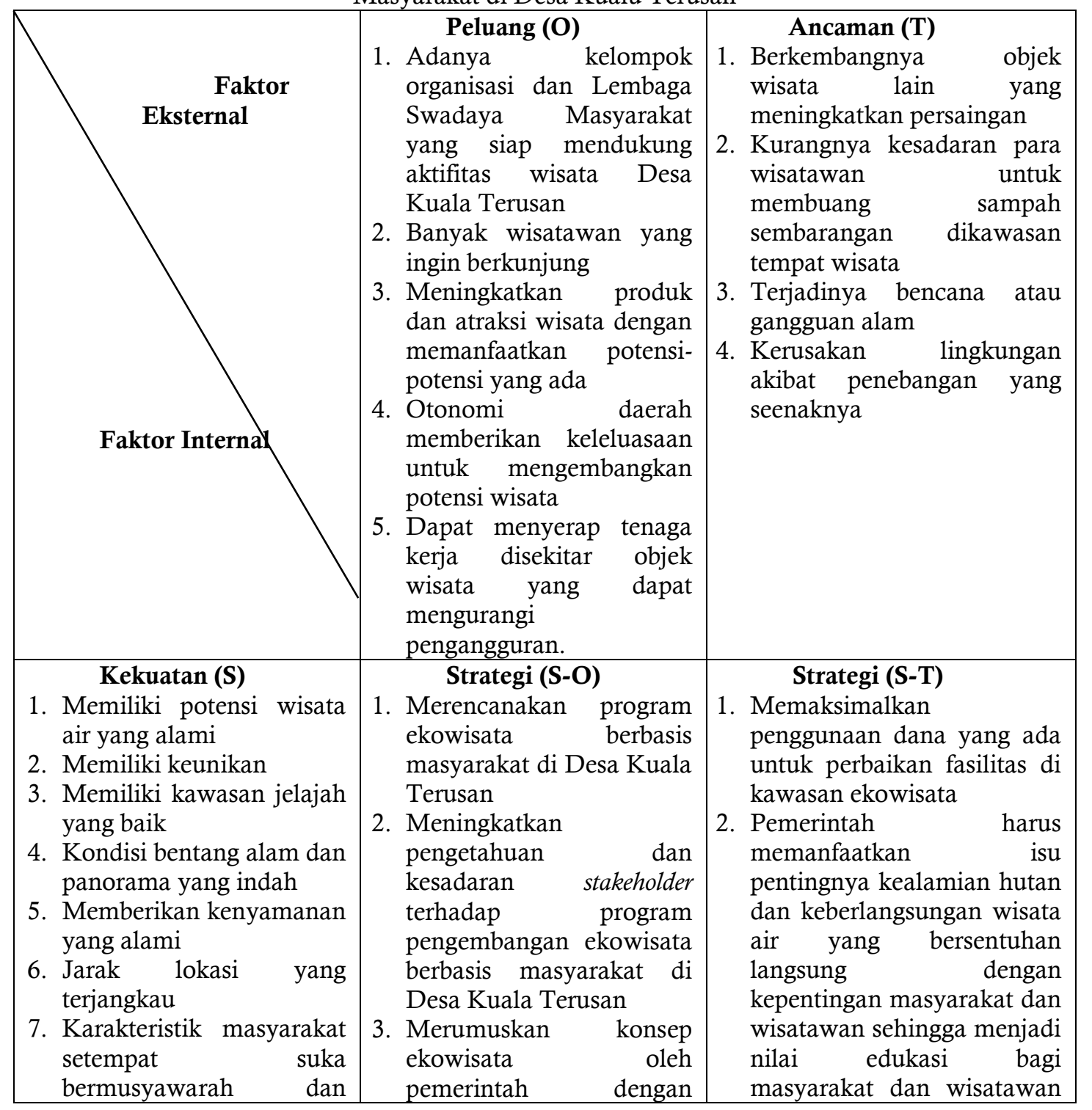




\begin{tabular}{|c|c|c|}
\hline $\begin{array}{l}\text { gotong royong } \\
\text { 8. Masih tersedia lahan } \\
\text { untuk perdagangan }\end{array}$ & $\begin{array}{l}\text { melibatkan kelompok- } \\
\text { kelompok organisasi dan } \\
\text { masyarakat melalui LSM } \\
\text { yang ada } \\
\text { 4. Memfokuskan } \\
\text { penyebarluasan informasi } \\
\text { terkait kondisi alam yang } \\
\text { unik, kealamiannya dan } \\
\text { pengamanan jalur yang } \\
\text { ada agar wisatawan yang } \\
\text { datang mempunyai kesan } \\
\text { yang baik saat berkunjung } \\
\text { secara langsung maupun } \\
\text { melalui media internet } \\
\text { 5. Meningkatkan ekonomi } \\
\text { masyarakat setempat dan } \\
\text { memfasilitasi masyarakat } \\
\text { untuk menempati lahan } \\
\text { untuk berdagang }\end{array}$ & $\begin{array}{l}\text { agar mau menjaga } \\
\text { ekosistem yang ada } \\
\text { 3. Memanfaatkan dan } \\
\text { menegakkan peraturan yang } \\
\text { ada untuk mendukung } \\
\text { program pengembangan } \\
\text { ekowisata berbasis } \\
\text { masyarakat di Desa Kuala } \\
\text { Terusan }\end{array}$ \\
\hline 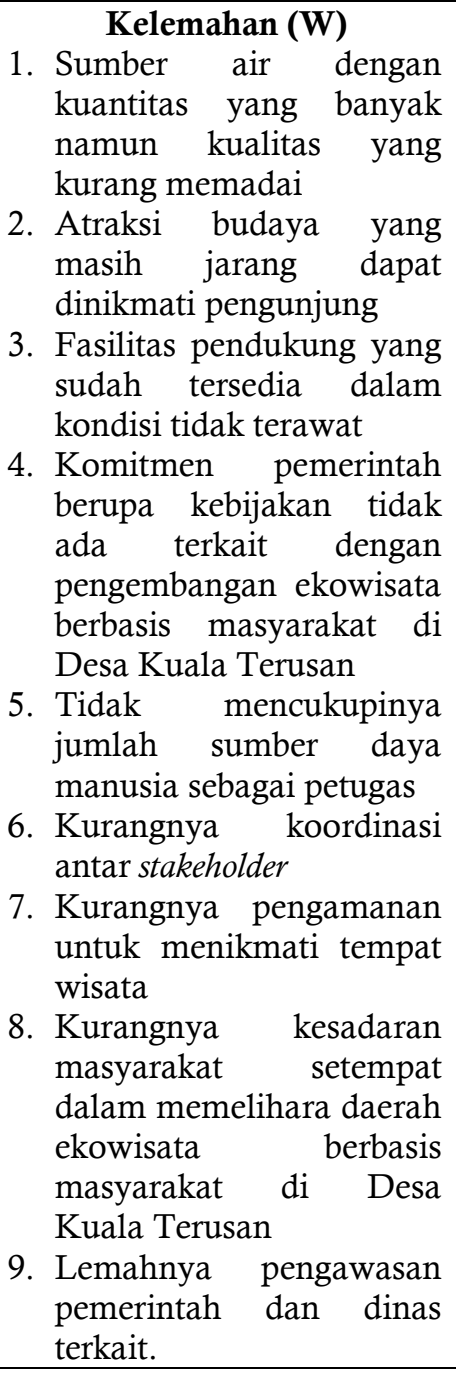 & 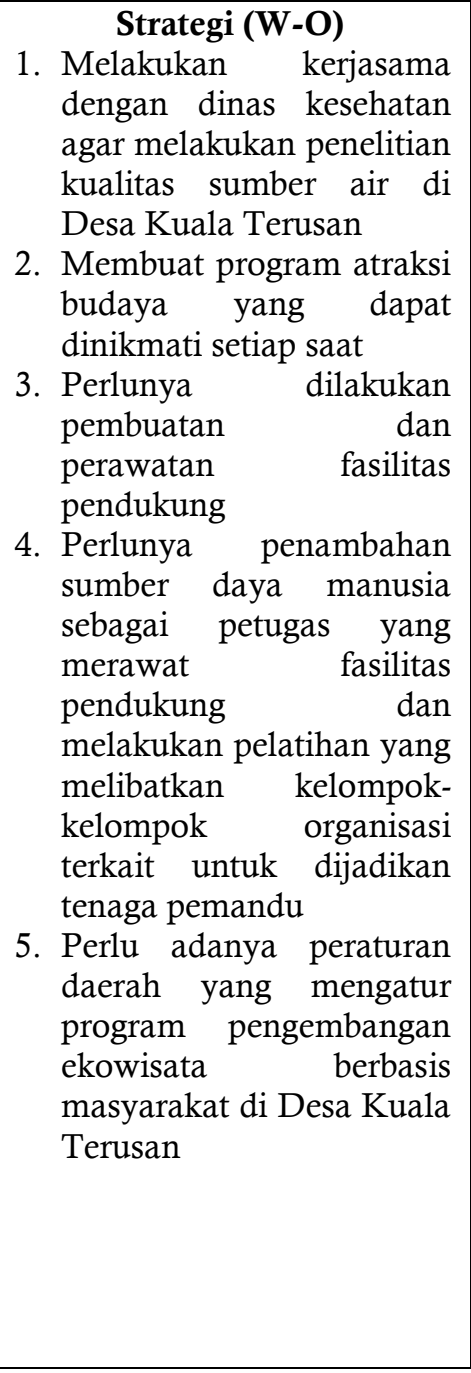 & $\begin{array}{l}\text { Strategi (W-T) } \\
\text { 1. Menyediakan fasilitas } \\
\text { kebersihan berupa tempat } \\
\text { sampah di beberapa titik } \\
\text { perhentian dan melakukan } \\
\text { edukasi singkat oleh } \\
\text { pemandu kepada wisatawan } \\
\text { agar membuang sampah } \\
\text { pada tempat yang telah } \\
\text { disediakan } \\
\text { 2. Pemerintah memanfaatkan } \\
\text { wisatawan untuk dikenalkan } \\
\text { pada potensi ekowisata air } \\
\text { sehingga keterlibatan } \\
\text { instansi terkait akan } \\
\text { memperkuat pengawasan } \\
\text { terhadap kelestarian hutan } \\
\text { alam dan kondisi perairan } \\
\text { untuk keberlangsungan } \\
\text { ekowisata berbasis } \\
\text { masyarakat di Desa Kuala } \\
\text { Terusan sosialisasi dan } \\
\text { 3. Perlunya sasaakat } \\
\text { pemberdayaan masyarakat } \\
\text { dalam program } \\
\text { pengembangan ekowisata } \\
\text { berbasis masyarakat di Desa } \\
\text { Kuala Terusan }\end{array}$ \\
\hline
\end{tabular}

Berdasarkan hasil analisa tersebut, maka diperoleh beberapa poin terkait strategi pengembangan Ekowisata berbasis masyarakat Desa Kuala Terusan sebagai berikut:

a. Merencanakan program pengembangan ekowisata berbasis masyarakat Desa Kuala Terusan.

b. Meningkatkan pengetahuan dan kesadaran stakeholder terhadap program pengembangan ekowisata berbasis masyarakat Desa Kuala Terusan.

c. Merumuskan konsep ekowisata dengan pemerintah serta melibatkan kelompok-kelompok masyarakat serta organisasi LSM yang ada. 


\section{ZONA}

Jurnal Lingkungan

ISSN : 2502-6496 (Print)

d. Meningkatkan ekonomi masyarakat setempat dengan memfasilitasi masyarakat untuk menempati lahan untuk berdagang.

e. Pemerintah perlu memanfaatkan isu pentingnya kealamian hutan dan keberlangsungan alam yang bersentuhan langsung dengan kepentingan masyarakat dan wisatawan sehingga menjadi nilai edukasi bagi masyarakat dan wisatawan agar mau menjaga ekosistem hutan yang ada.

f. Memanfaatkan dan mengetakkan peraturan yang ada untuk mendukung program pengembangan Ekowisata berbasis masyarakat Desa Kuala Terusan.

\section{Community Based Ecotourism}

Community Based Ecotourism merupakan konsep pengembangan ekowisata dengan melibatkan dan menempatkan masyarakat lokal yang mempunyai kendali penuh dalam manajemen dan pengembangannya sehingga memberikan kontribusi terhadap masyarakat berupa peningkatan kesejahteraan masyarakat lokal dan keberlanjutan kebudayaan lokal. Desa Kuala Terusan dengan objek wisata utama yaitu ekowisata. Bentuk partisipasi masyarakat terhadap keberadaan objek wisata dapat berupa partisipasi secara langsung, yaitu masyarakat ikut terlibat dalam pengelolaan dan pemeliharaan objek wisata, sebagai berikut:

a. Penduduk sekitar ikut berpartisipasi dalam usaha makanan dan minuman serta bersedia memasak langsung hasil tangkapan perairan dari pengunjung. Selain itu masyarakat juga dapat memasak makanan sesuai permintaan pengunjung.

b. Penduduk sekitar menyediakan rumahnya sebagai tempat penginapan para pengunjung yang ingin bermalam di kawasan Desa Kuala Terusan.

c. Penyediaan lahan parkir kendaraan di halaman rumah masyarakat atau di lapangan.

d. Masyarakat ikut berpartisipasi dalam pembuatan dan penjualan berbagai cenderamata, penjaga parkir maupun pemandu jalan di kawasan Desa Kuala Terusan.

Berdasarkan kajian yang dilakukan, terdapat beberapa poin penting yang masih menjadi pekerjaan rumah bagi pemerintah dan berbagai pihak terkait dalam upaya pembangunan kawasan geopark agar dapat sejalan dengan upaya pembangunan daerah di sekitarnya, yaitu sebagai berikut:

a. Meningkatkan kapasitas infrastruktur guna memudahkan para wisatawan untuk menuju objek wisata serta mengembangkan potensi-potensi objek wisata yang dibutuhkan oleh para wisatawan.

b. Pemerintah provinsi perlu segera memperhatikan objek wisata unggulan ini, karena fasilitas kegiatan wisata dan lingkungan yang ada di kawasan wisata ini sangat minim, sehingga masih kurang nyaman dan amannya untuk dikunjungi

c. Pemerintah perlu melakukan kerjasama dengan pihak swasta dan masyarakat, terutama untuk pendanaan dan pengelolaan lingkungan objek wisata.

d. Mempromosikan secara kontinue dengan event-event tahunan dan juga melakukan promosi melalui media cetak dan elektronik

e. Meningkatkan kemampuan sumber daya manusia di lokasi objek wisata agar dapat menciptakan karya-karya kreatif, sebagai daya tarik bagi para wisatawan untuk berkunjung dan mau membelanjakan uang mereka atas hasil karya masyarakat setempat.

f. Dalam upaya mengantisipasi terjadinya bencana yang tidak dapat diperkirakan, dapat disiasati dengan upaya memberikan penyuluhan dan pelatihan terhadap masyarakat lokal ketika terjadi bencana dan juga meningkatkan kualitas fasilitas yang berbasiskan mitigasi bencana, agar wisatawan tetap merasa aman.

Berkaitan dengan kualitas lingkungan, maka pemeliharaan lingkungan alam menjadi prioritas. Kesadaran masyarakat sekitar kawasan Desa Kuala Terusan perlu ditumbuhkan dan dipelihara, sekaligus meningkatkan kapasitas sumber daya manusianya dalam mengelola lingkungan kawasan wisata tersebut.Pengembangan desa wisata di kawasan Desa Kuala Terusan menjadi salah satu alternatif dalam upaya pemeliharaan lingkungan sekaligus peningkatan kondisi sosial ekonomi masyarakatnya.

\section{KESIMPULAN}

Flora yang terdapat di Kuala Terusan merupakan jenis hutan gambut dan hutan rawa air tawar sehingga tidak ada flora khusus yang merupakan ciri khas daerah Desa Kuala Terusan, jenis fauna di Kuala Terusan berupa hewan reptile, mamalia, burung dan jenis ikan yang ada di aliran sungai Kampar.

Berdasarkan hasil perhitungan daya dukung fisik (Physical Carrying Capacity/PCC) didapatkan nilai PCC untuk aktivitas berenang/snorkeling dapat menampung 40 orang/hari artinya sungai Kuala Terusan yang digunakan untuk area pemanfaatan berenang seluas $5.000 \mathrm{~m}^{2}$ dengan total waktu 8 jam yang disediakan kawasan selama satu hari, dan waktu yang digunakan wisatawan untuk berenang selama 2 jam, 


\section{ZONA}

Jurnal Lingkungan

Volume 4, No 2, Oktober 2019, p. 58-70

ISSN : 2502-6496 (Print)

http://zona.pelantarpress.co.id

maka jumlah wisatawan yang dapat ditampung untuk aktivitas berenang pada lokasi tersebut adalah 40 orang dalam satu hari. Aktivitas berenang di Kuala Terusan ini dapat dikategorikan over carrying capacity karena jumlah wisatawan yang melakukan aktivitas wisata melebihi daya tampung yang tersedia.

Aktifitas yang dilakukan oleh para pengunjung wisata Kuala Terusan diantaranta wisata pantai dan piknik keluarga. Lokasi piknik keluarga dan wisata pantai memiliki area pemanfaatan seluas $3.000 \mathrm{~m}^{2}$. Daya dukung yang dapat menampung wisatawan untuk aktivitas wisata pantai adalah sebanyak 240 orang/ hari. Sarana fasilitas masih perlu adanya perbaikan seperti halnya dalam pengolahan sampah yang belum berjalan dengan baik.

1. Strategi pengembangan ekowisata berbasis masyarakat (CBE) di Desa Kuala Terusan Kabupaten Pelalawan meliputi:

a. Merencanakan program pengembangan ekowisata berbasis masyarakat Desa Kuala Terusan

b. Meningkatkan pengetahuan dan kesadaran stakeholder terhadap program pengembangan ekowisata berbasis masyarakat Desa Kuala Terusan.

c. Merumuskan konsep ekowisata dengan pemerintah serta melibatkan kelompok-kelompok masyarakat serta organisasi LSM yang ada.

d. Mengembangkan makanan (jajanan lokal khas daerah Kuala Terusan) dengan mengikut sertakan ibu-ibu melalui PKK di Desa Kuala Terusan.

e. Meningkatkan ekonomi masyarakat setempat dengan memfasilitasi masyarakat untuk menempati lahan untuk berdagang.

f. Pemerintah perlu memanfaatkan isu pentingnya kealamian hutan dan keberlangsungan alam yang bersentuhan langsung dengan kepentingan masyarakat dan wisatawan sehingga menjadi nilai edukasi bagi masyarakat dan wisatawan agar mau menjaga ekosistem hutan yang ada.

\section{DAFTAR PUSTAKA}

Dinas Kebudayaan, Pariwisata, Pemuda dan Olahraga Kabupaten Pelalawan. 2015. Potensi Pariwisata Kabupaten Pelalawan 2015 http://disbudparpora.pelalawankab.go.id/. Diunduh (16 Maret 2020).

Kementerian Pariwisata Ekonomi Kreatif. 2012. Rencana Strategis Pariwisata Berkelanjutan dan Green Jobs untuk Indonesia. (ID): Kemenparekraf. Jakarta.

Kristiana Y. Theodora dan M. Stephanie. 2016. Strategi Upaya Pengembangan Pariwisata Berkelanjutan Agrowisata Berbasis Masyarakat Kampung Domba Terpadu Juhut, Provinsi Banten. Jurnal Penelitian, 3 (2) 2338-3321.

Linberg K, Hawkins DE. 1995. Ecotourisme: Petunjuk untuk Perencana dan Pengelola. The Ecotourism Society. North Bennington.

Lucyanti, S. 2013. Strategi Pengembangan Objek Wisata Alam Bumi Perkemahan Palutungan Berdasarkan Pendekatan Daya Dukung Lingkungan di Taman Nasional Gunung Ciremai. Tesis. Program Pascasarjana Universitas Diponegoro. Semarang. (tidak diterbitkan).

Miles, B. dan M. Huberman. 1992. Analisis data kualitatif: Buku Sumber Tentang Metode-Metode Baru. Universitas Indonesia Press. Jakarta.

Moleong, J. L. 1989. Metodologi Penelitin Kualitatif. PT. Remaja Rosdakarya. Bandung.

Muallisin, I. 2007. Model Pengembangan Pariwisata Berbasis Masyarakat di Kota Yogyakarta. Jurnal Penelitian,

Nurdin. 2016. Strategi Pengembangan Pariwisata Berbasis Masyarakat Di Pulau Samalona, Makassar. Prodi Magister Kajian Pariwisata Universitas Udayana Sekolah Tinggi Pariwisata Tamalatea Makassar. Jurnal Penelitian, 3 (1) : 175 - 189.

Pelalawan tourism. Welcome to Pelalawan. 2016. Danau Tanjung Putus Terletak di Kecamatan Pangkalan Kerinci. http:// pelalawantourism.com. Diunduh (21 Maret 2017- 20.00 WIB).

Permendagri. 2009. Peraturan Menteri Dalam Negeri Republik Indonesia Nomor 33. Tahun 2009 Tentang Jenis-jenis Ekowisata di Daerah. Kementerian Dalam Negeri Republik Indonesia. Jakarta.

Rahardyan, B. dan Widagdo, A. S. 2005. Peningkatan pengelolaan persampahan perkotaan melalui pengembangan daur ulang. Materi Lokakarya 2 Pengelolaan Persampahan di Provinsi DKI Jakarta. Jakarta. 


\section{ZONA}

Jurnal Lingkungan

Volume 4, No 2, Oktober 2019, p. 58-70

ISSN : 2502-6496 (Print)

http://zona.pelantarpress.co.id

Rangkuti. 1997. Analisis SWOT Teknik Membedah Kasus Bisnis. Gramedia Pustaka Utama. Jakarta.

Riau Pos. 2016. Pariwisata Riau Mulai Menyapa Dunia. http://riaupos.co/galeri/29-calender-of-event-riau2016.html. Diunduh (31 Mei 2017 - 10.54 WIB).

Saaty, T. L. 2008. Decision making with the analytical hierarchy process. International Journal Services Sciences.

Santoso, Bambang. 2014. Strategi Pengembangan Ekowisata Berdasarkan Daya Dukung Lingkungan Di Taman Nasional Bukit Tigapuluh Propinsi Riau. Tesis. Program Pasca Sarjana Ilmu Lingkungan Universitas Diponegoro. Semarang. (tidak diterbitkan).

Suansri, P. 2003. Community Based Tourism Handbook. REST Project. Thailand.

Syafi'I M., Suwandono D. 2015. Perencanaan Desa Wisata Dengan Pendekatan Konsep Community Based Tourism (CBT) Di Desa Bedono, Kecamatan Sayung, Kabupaten Demak. Universitas Diponegoro. Semarang. Jurnal Undip Ruang Volume, 1 (2) : 51- 60.

Undang-Undang Nomor 32 Tahun 2009 Tentang Perlindungan dan Pengelolaan Lingkungan Hidup. Jakarta.

Undang-Undang Nomor 18 Tahun 2008 Tentang Pengelolaan Sampah. Jakarta.

Undang- Undang No. $10 \mathrm{Ta}$ hun 2009 Tentang Kepariwisataan Pemerintah Republik Indonesia. Jakarta.

Yulianda, F. 2007. Ekowisata Bahari Sebagai Alternatif Pemanfaatan Sumberdaya Pesisir Berbasis Konservasi. IPB. Bogor. 